\title{
O difícil diálogo entre escola e mídia
}

Juvenal Zanchetta Junior'

\section{Resumo}

Desde a década de 1930, quando o Estado Novo organiza a escola básica e superior no país, e também momento em que se esboça o modo como os meios de comunicação de massa viriam a tratar do tema da educação, escola formal e mídia sempre percorreram caminhos distintos, embora a finalidade educativa faça parte determinante do estatuto das duas instituições. Nesta pesquisa, investigamos os motivos que levaram a essa característica, principalmente no que diz respeito à escola secundária. Entre as principais razões para o distanciamento está o isolamento da escola secundária em relação à mídia, resultante da legislação regulatória e das tendências pedagógicas para a ação escolar. As principais referências para a análise foram a legislação e orientações curriculares federais para a escola secundária (1930-2016), os livros didáticos voltados para a disciplina de português (19702016), e a Revista Brasileira de Estudos Pedagógicos (1940-1970). Entre as constatações mais gerais estão a secundarização da estratégia de aproximar escola e mídia por meio da franca opção por veículos e projetos próprios do Estado (tendência determinante desde a década de 1930); e a crescente exposição de textos midiáticos no cotidiano das ações pedagógicas a partir dos anos 1970, mas com predomínio de atividades voltadas ao atendimento do currículo regular, distantes da avaliação do contexto midiático.

\section{Palavras-chave}

Educação formal - Escola - Mídia - Meios de comunicação.

I- Universidade Estadual Paulista "Júlio de Mesquita Filho" (Unesp), Assis, São Paulo, Brasil.

Contato: jzancheta@gmail.com 


\title{
The difficult dialogue between secondary school and the Media in Brazil
}

Juvenal Zanchetta Junior'

\begin{abstract}
Since the 1930s, when the Estado Novo organized the secondary and higher school in Brazil, and also when it outlined how the mass Media would come to address the issue of education, formal school and Media have always gone different ways, although the educational purpose is a determining factor to the two institutions. In this paper, we investigate the reasons to this characteristic, especially with regard to secondary school. The main reason for that distancing is the isolation of secondary school in relation to the Media, because of the regulatory legislation and the pedagogical tendencies for the school action. The references for the analysis were the federal curricular legislation and guidelines for secondary school (1930s-2016s), the textbooks for Portuguese (1970s-2016s), and the journal Revista Brasileira de Estudos Pedagógicos (1940s-1960s). Among the more general findings are the secondary strategy of approaching school and the Media through the option for vehicles and projects of the state (a determining tendency since the 1930s); and the increasing exposure of Media texts in the daily life of pedagogical actions from the 1970s, but with a predominance of activities aimed at attending the regular curriculum, far from the evaluation of the media context.
\end{abstract}

\section{Keywords}

Formal education - Secondary school - Media.

I- Universidade Estadual Paulista

"Júlio de Mesquita Filho" (Unesp),

Assis, São Paulo, Brasil.

Contact: jzancheta@gmail.com 


\section{Introdução}

A escola é a instituição responsável pela formação educacional no Brasil, mas os demais agentes públicos devem contribuir para tanto. Entre eles, estão canais oriundos de concessão pública, como os de televisão (abertos e fechados) e de rádio, e aqueles que se utilizam do espaço de telefonia (sobre o qual se estabelece a internet) ${ }^{1}$. 0 Regulamento dos Serviços de Radiodifusão (RSR) destaca tal responsabilidade:

Art. $3^{\circ}$ : Os serviços de radiodifusão têm finalidade educativa e cultural, mesmo em seus aspectos informativo e recreativo, e são considerados de interesse nacional, sendo permitida, apenas, a exploração comercial dos mesmos, na medida em que não prejudique esse interesse e aquela finalidade. (RSR, 1963)².

Mesmo que haja um terreno intermediário entre as noções de educação e de educação formal, ele não é elástico a ponto de justificar distância tão grande entre os percursos da escola e dos meios de comunicação (MC) no país.

Uma das mais visíveis explicações para essa distância relaciona-se à histórica carência de recursos para a exploração de suportes e textos midiáticos na escola. Apenas em décadas recentes, jornais, televisão e rádio entraram para o cotidiano escolar, por meio de iniciativas localizadas. A falta de equipamentos, por sua vez, em boa parte decorre de fator mais complexo: a legislação regulatória dessas duas instituições. Em outro estudo, observamos como as leis e as regras originadas dos MC preservam a mídia de compromissos educacionais mais consistentes, graças à contínua tergiversação do patronato dessa área, comprometido apenas com ações educativas pontuais e demandas de mercado,

1- Jornais impressos não são objeto de concessão, mas, ligados a organizações maiores, se beneficiam do apoio de canais cedidos pelo Estado. 2- 0 decreto 21.111/32, que regulamentou o serviço de rádio, era ainda mais categórico em relação à finalidade educacional (cf. art. 11). algo possível em razão do caráter tangencial da legislação que relaciona educação, escola e mídia (ZANCHETTA, 2015). Tratamos aqui de outra frente que ajuda a compreender o problema: como a própria história da escola brasileira contribuiu para mantê-la longe dos MC.

Destacamos aspectos da escolarização secundária, equivalente hoje às séries finais do ensino fundamental (EF) e ao ensino médio (EM), desde a década de $1930^{3}$. Os MC são abarcados em cenário abrangente, a que chamamos mídia, constituído pelo conjunto formado por televisão, rádio, cinema, jornais e revistas impressos e digitais, entre outros MC que permitem a difusão de informações noticiosas e de entretenimento, no trabalho particular de cada veículo, em concomitância com outros veículos ou em rede. Textos midiáticos são os produzidos ou difundidos pelos mesmos canais. Distinguimos, para efeito didático, os veículos privados, chamados de MC comerciais, e os estatais, tratados como veículos educativos. Ao longo de um século, mudaram as perspectivas acerca da noção de texto, mas, desde o século XIX, excertos de romances, poemas, contos, fábulas e crônicas colocaram-se no centro das atividades pedagógicas e já eram tratados como gêneros textuais nas obras didáticas (cf. ROJO, 2008).

Como base para as considerações seguintes, utilizaram-se as orientações curriculares federais para a disciplina de português, a legislação correspondente, os livros didáticos (LD) voltados àquela disciplina e a Revista Brasileira de Estudos Pedagógicos (RBEP). Mais longeva publicação políticopedagógica do país, a RBEP foi consultada em números publicados até 1970, com destaque para os artigos e as seções "Notícia do País", "Notícia do Estrangeiro" e "Através de jornais e revistas", quando trataram de papéis educacionais para rádio, jornais, cinema e televisão. Para esboço sobre o período posterior,

3- Antes da organização escolar promovida por Vargas, o ensino secundário não era obrigatório para ingresso no ensino superior (ROMANELLI, 1986, p. 135) e estava limitado a algumas escolas, na maioria privadas (situação que só mudaria na década de 1980) (CURY, 1991). 
foram consultados LD de português, por refletirem de maneira imediata as normas e as tendências pedagógicas predominantes ${ }^{4}$. Sobre o período entre 1970 e 1990, as observações estão centradas em obras das editoras então responsáveis por 90\% do mercado de $\mathrm{LD}^{5}$. Para a análise da situação recente, foram tomadas as coleções mais distribuídas no país entre os anos de 2012 a 2014, dentro do Programa Nacional do Livro Didático (PNLD) e do Programa Nacional do Livro Didático para o Ensino Médio (PNLEM). Cerca de 140 coleções didáticas do período 1970-2014 foram consultadas. Esperase que a informação disposta em cada tópico justifique a periodização adotada.

\section{0 a 1970}

Um fator determinante da relação entre mídia e escola, com reflexos mesmo nos dias de hoje, está na diretriz conformada desde a década de 1930: o desenvolvimento de veículos e mecanismos estatais voltados à tarefa de educar e ao controle sobre os textos escolares, secundarizando papel educador da mídia. Não cabe aqui discussão aprofundada do quadro histórico daquele período, sobre o qual existe farta literatura, mas destacar aspectos que ajudaram a consolidar aquela diretriz.

Voltar-se para meios próprios do Estado evitava o ruído da imprensa combativa e da crônica apressada, a opinião política dissonante dos MC mais influentes e das agências de publicidade norte-americanas, que traziam ainda estrangeirismos em excesso. Incentivava-se a expressão oral, característica da cultura do país, observada desde os textos literários adaptados para a leitura em voz alta

4- A ausência de textos midiáticos nos LD anteriores a 1970 faz deles fonte secundária, mas cerca de quarenta obras do período 1930-1970 foram consultadas para informação complementar aos estudos de Razzini (2000) e Soares (2001), que estão entre as contribuições centrais para a compreensão daquela época.

5- Nos anos 1980, oito editoras eram responsáveis por $91 \%$ das obras didáticas dentro do PNLD: Companhia Editora Nacional/IBEP (responsável por $33 \%$ do conjunto), Editora do Brasil (26\%), Ática (10\%), FTD (9\%), Saraiva (6\%), Caminho Suave (3,5\%) e Scipione (3,5\%) (Leia Livros, 1986, n. 41), Tais editoras, também destacadas por Freitag, Mota e Costa (1989), foram consultadas, com exceção da Caminho Suave.
(CANDID0, 1985), até a presença volumosa de notas, folhetins e crônica cotidiana nos jornais desde o século XIX (facilitavam a leitura em voz alta por terceiros), passando pelo vigor do rádio e da televisão, prestigiados até os dias de hoje (SECOM, 2014), pelas tiragens expressivas de revistas ilustradas e pelos textos para declamação e canto das obras didáticas que chegaram aos anos 1960.

Mas isso ocorria de forma controlada, com emissões seletivas e qualificadas (CALABRE, 2003). Havia apenas cinco emissoras de rádio oficiais entre as 63 criadas entre 1923 e 1937, mas seu conteúdo sobressaía no conjunto da programação. 0 governo federal controlava a principal emissora, a Rádio Nacional (que alcançava todo o país), além de fazer da Voz do Brasil um programa obrigatório para todas as emissoras. Quanto ao cinema, desde 1932 havia obrigatoriedade de exibição de complemento nacional nas fitas de longa-metragem. No mesmo ano, instalou-se a primeira Comissão de Censura Federal. Deixavam-se de lado os programas populares do rádio, boa parte dos filmes norte-americanos e, mais tarde, a televisão comercial, que, além do avanço lento ${ }^{6}$, importaria formatos radiofônicos (MICELI, 2003; BAHIA, 1990; SODRÉ, 1966).

A opção por veículos estatais e por emissões seletivas contribuiria para outros aspectos educacionais: a) enfrentaria o problema do analfabetismo; b) uniformizaria a conduta pedagógica, o que incluía a consolidação do ideário escolanovista; c) por meio dos princípios da Escola Nova, estimularia aprendizado menos dependente do conhecimento do professor, contornando o problema da falta e da precariedade da formação dos professores, sobretudo nas áreas rurais ou distantes dos centros maiores, e no ensino supletivo; d) promoveria a assepsia nos conteúdos de modo a ressaltar valores culturais e morais prestigiados; e) aproximaria a escola do cotidiano de uma sociedade mais urbana e industrializada; f) não se distanciaria do exemplo de países que se desenvolviam

6- Em 1957, o país tinha cerca de quinhentos mil aparelhos e população de setenta milhões de habitantes. 
rapidamente (europeus e norte-americanos), onde havia exemplos de aproximação entre a escola e a mídia ${ }^{7}$.

Nomes importantes da política educacional $^{8}$ chancelavam o uso da tecnologia para o ensino. Daí, por exemplo, a criação do Instituto Nacional de Cinema Educativo (INCE), em $1937^{9}$, do Serviço de Radiodifusão Educativa, da Universidade do Ar (1941-1943), do Sistema de Rádio Educativo Nacional (Sirena) (1957-1963) e, mais tarde, do Projeto Minerva. Inspirados no modelo estadunidense (BEKER, 1967) destaquem-se, além do Setor de Rádio e Televisão Educativa (Serte) (1965), as iniciativas estaduais, como a fundação da TV Cultura, em São Paulo (1969).

Críticas aos MC comerciais não eram incomuns, como nas recomendações feitas pelos participantes do I Congresso Estadual de Educação de São Paulo, em 1957:

Estimular jornais infantis, proibindo-se conteúdos alheios aos interesses da criança...

Tomar providências, no sentido de que se use o vernáculo corretamente nos jornais, revistas, rádio, televisão e cinema...

Sugerir às rádio-emissoras modificação dos "Programas Caipiras", para evitar a difusão do português mal falado. (RBEP, 1957, p. 122).

A revista Cultura Politica (Estado Novo) criticava recorrentemente o rádio então praticado: "tanto o setor de radiodramatização, quanto o de 'locução' deveriam sofrer uma

\footnotetext{
7- A seção "Notícia do Estrangeiro", desde os anos 1940 apresentava sistematicamente iniciativas de países europeus e norte-americanos nessa área. 8- A Rádio Escola Municipal do Distrito Federal foi criada em 1933, na gestão de Anísio Teixeira. Na mesma época, Fernando de Azevedo organizou em São Paulo o Serviço de Rádio e Cinema Educativos. Lourenço Filho promoveu o cinema educativo nas escolas públicas paulistas em 1931, e fez parte da primeira Comissão de Censura Federal do Ministério da Educação (ANTONACCI, 1993). As Conferências Internacionais de Instrução Pública, cujas sugestões eram divulgadas pela RBEP, insistiam, desde os anos 1930 no uso desses meios para o fomento da educação (BRASIL, 1965).

9- Seu regimento foi oficializado pelo Decreto 20.301/1946. Um dos fatores que inspiraram o INCE foi a experiência de instrução por meio de filmes educativos realizada pelos Estados Unidos durante a Segunda Guerra. (cf. FULCHIGNONI, 1953).
}

intervenção mais radical com relação aos problemas da linguagem - qualidade de vocabulário, pronúncia e concordância em geral" (CALABRE, 2003, p. 10).

Entre os anos 1944 e 1945, a RBEP publicou estudos sobre os suplementos infantis e juvenis dos jornais e revistas da capital do país. 0 principal alvo eram os textos de literatura infantil neles predominantes. As instruções incluíam orientação minuciosa sobre como deveriam se constituir as narrativas. Não havia concessão sequer para as historietas de mocinhos e bandidos, comuns no período (RBEP, 1945, p. 233).

0 controle era bem maior sobre a ação escolar. 0 isolamento da escola em relação aos MC comerciais tinha raízes no próprio currículo. As antologias que chegaram até os anos 1960 guardavam espaço para a gramática normativa $\mathrm{e}$ para o cânone literário, chancelados pelo currículo acadêmico e retórico da escola que chegou até os anos 1930 (SOUZA, 1999) e pelo currículo enciclopédico cuja influência alcançou os anos $1980^{10}$. O programa de ensino do Colégio Pedro II, referência para os estudos secundários desde o século XIX ${ }^{11}$, na década de 1940, continha traços que vinham desde o início do século e persistiriam até os anos 1960:

A leitura admitida nas aulas de português do $2^{\circ}$ ciclo era só a leitura literária, centrada na transmissão da história da literatura portuguesa e brasileira, por isso ela abrangia [...] "desde trovadores medievais até escritores do século XX”. Sua função tradicional, de ponto de partida para outras atividades, foi preservada. (RAZZINI, 2000, p. 105).

Os exercícios de leitura restringiam-se aos textos literários e à "expressão escrita", baseada em exercícios calcados nos mestres da literatura:

10- 0 ensino secundário, reformado o início dos anos 1930, passou a contar com mais de cem disciplinas, anuais, avaliadas por: a) arguição mensal; b) prova parcial a cada dois meses; c) exame final (ROMANELLI, 1986, p. 137).

11- Decreto $19.890 / 31$, art. $10^{\circ}$, com redação alterada pelo Decreto $21.241 / 32$ 
1. Em todo este curso de português o professor se esforçará por incutir nos alunos o amor da língua, o zelo dela traduzido no desejo de manejá-la bem e de protegê-la das forças dissolventes que estão continuamente a assaltá-la.

2. Sobre os fará respeitosos da sua modalidade mais nobre, a língua literária, visto ser esta a de mais importante papel social e político e, ao mesmo tempo, um dos mais fortes fatores do progresso [...]. ${ }^{12}$

Por conflituosa que fosse a relação entre o ensino de literatura e o de gramática, sobretudo depois da década de 1930 (COUTINHO, 1954), os textos literários serviam de porto seguro estético e moral para os exercícios predominantes de redação descritiva e narrativa. Mesmo com a diminuição do espaço dedicado à historiografia, a literatura pautava os relatos orais e os cada vez mais prestigiados exercícios de redação ${ }^{13}$. Além da imitação dos mestres, da expressão eloquente, do tom patriótico e nacionalista, da memorização de conteúdos reconhecidos universalmente, deveria prevalecer, marcadamente a partir dos anos 1940, o estudo gramatical, que levaria ao "escrever bem" (PIETRI, 2010). Havia pouco espaço para os conteúdos prosaicos e fluidos do jornal, do cinema do rádio e da televisão.

Além da tradição beletrista, havia filtros morais e de uso da linguagem. A Comissão Nacional do Livro Didático (CNLD), criada em 1937, tinha sua composição baseada em nomes do Colégio Pedro II, Colégio Militar, Escola Naval e Instituto de Educação do Distrito Federal (FERREIRA, 2007) - instituições que perpetuavam os valores escolares vigentes. Embora com problemas para funcionamento, como o excesso de rigor nas avaliações, a CNLD podia excluir livros por desvios ideológicos e por quaisquer conteúdos que não se mostrassem edificantes ${ }^{14}$. "Deixem que os educadores

12- Portaria Ministerial n.172/1942, relativa às instruções metodológicas para o programa de português.

13- Portaria 190, fevereiro de 1940, Departamento Nacional de Educação. 14- Artigo 21 , decreto-lei $1.006 / 1938$. eduquem, pelo amor de Deus!" foram as palavras de Lourenço Filho (1958, p. 45), em artigo incomodado com o sensacionalismo da imprensa. 0 constrangimento provocado por uma aluna que fixou na porta da sala de aula uma foto de índios nus, publicada em $O$ Cruzeiro, chegou aos jornais:

Parece-nos que os jornais ou as publicações destinadas ao público deviam abster-se de gravuras excitantes, intensamente sensuais ou pouco convenientes à formação moral da juventude. Mais grave ainda e maiores prejuízos causam ao bom caráter e à educação da mocidade as revistas humorísticas em que as anedotas, as gravuras, o texto, enfim, são imundas demonstrações da [...] corruptora pornografia e perigosas formas de perversão dos jovens estudantes... (GOMES, 1947, p. 555-6).

0 primeiro Acordo Ortográfico entre Brasil e Portugal aconteceu em 1931, materializou-se como norma em 1943, e sofreu influência das modificações promovidas por Portugal em 1945. A gramática apresentava conflitos de interpretação, somente resolvidos com a publicação da portaria ministerial 152/57, que estabelecia a Nomenclatura Gramatical Brasileira, em vigor a partir de 1959. Manuais didáticos explicavam e defendiam pontos de vista relacionados ao uso da língua e das palavras, e voltavam-se não apenas para estudantes, mas também para jornalistas e funcionários públicos (cf. LEAL, 1955). A sugestão de Câmara Jr. para o uso culto da língua levava em conta essa diversidade de regras: "Em matéria de correção de linguagem [...] não [devemos] dar a impressão de que somos originais na maneira de falar ou escrever" (1966 [1961], p. 118).

Alternativa para aproximar a escola da informação que circulava na sociedade estava em jornais e revistas escolares, estimulados por meio de agências como a Divisão de Educação ExtraEscolar do Departamento Nacional de Educação ${ }^{15}$,

15- A Portaria 583/1963 do MEC incumbia a Divisão de Educação Extra-Escolar de "registro de órgãos de imprensa estudantil e de cursos 
e que chegaram a ser institucionalizados pelo governo federal ${ }^{16}$. Na resposta a críticas sobre problemas em Santa Catarina, descortinam-se o peso e o espaço atribuídos às publicações escolares:

Verificou o Departamento o seguinte: 1) que as associações auxiliares da escola vêm, na sua mor parte, sendo dirigidas e executadas, em tudo e por tudo, pelo professor; 2) que a colaboração dos alunos tem sido nula; 3) que o professor executa todo o serviço, aparecendo somente o aluno, "in nomine"; 4) que há jornal escolar feito exclusivamente pelo professor (redação etc.) [...]; 5) que os recortes para os alunos são feitos pelo professor [...]. Tudo é feito pelo professor e o aluno assina, como se fosse seu trabalho. 0 Departamento de Educação conhece os seguintes argumentos de professores, para justificarem esse modo de ação: [...] 3) que o jornal pode ficar deficientemente redigido; 4) que, ao passar as notícias e artigos para o jornal, o aluno pode copiar mal, má letra e mau desenho, e além da diversidade de letra (três ou quatro alunos, em escrevendo no jornal, prejudica-se a estética do mesmo). (MELO, 1956, p. 106).

Os conteúdos escolares reproduziam o roteiro proposto pelas publicações juvenis realizadas por jornais, em que predominavam contos e historietas (quase a metade dos textos), ensinamentos gerais e quadrinhos (RBEP, 1944). A Vitória Colegial, revista escolar premiada na II Exposição Brasileira de Publicações Estudantis, em 1955, dedicava-se quase inteiramente a propósitos confessionais (CHAVES, 2012). Embora voltadas para professores e acompanhando de perto as normas da vida docente, a Revista do Magistério (1952-1963) e a Revista do Professor (1949-1965, segunda fase da revista) também destacavam temas morais e o caráter edificante da educação.

extraescolares que visem ao preparo técnico e cultural do estudante para 0 desempenho de lides relacionadas com o jornalismo estudantil".

16- Oficializados pelo Decreto 2.911/1956, que instituiu as associações auxiliares da escola.
Referências curriculares a textos midiáticos eram discretas. Havia anotações secundárias quanto à produção de artigos jornalísticos pelos estudantes, incluídos entre as tarefas escolares ${ }^{17}$. 0 rádio e o cinema comerciais eram incentivados na educação supletiva ou de adultos. Restava o trabalho de escolas e professores, em ações isoladas, como no desenvolvimento de hemerotecas, filtradas pelos aspectos já comentados.

Embora localizadas nos principais centros urbanos, onde a presença e participação dos MC eram mais intensas, as escolas secundárias apareciam na imprensa em notas relativas a efemérides promovidas por associações escolares ou por informação sobre a rotina legal dos estabelecimentos. Havia discussão de questões de fundo, como a gratuidade do ensino secundário ou a merenda escolar, mas nos espaços dedicados à educação, como na seção "Ensino", do jornal Correio da Manhã, predominavam temas do ensino superior ${ }^{18}$. Xavier (2005) sugere ação semelhante em outros jornais cariocas nos anos 1950.

As antologias buscavam excertos que pudessem interessar os secundaristas pelos títulos e temáticas vigorosos, como "Ladrões" (Padre Vieira), "Gladiadores" (Padre Manuel Bernardes) e "Muralha da China" (Fernão Mendes Pinto) (cf. ALMEIDA, 1946). "A execução de Tiradentes”, de João Ribeiro, texto aproveitado em várias antologias, mesmo tendo sido escrito por volta de $1900^{19}$, avizinhava-se da crônica dos jornais da década de 1950. Manuais arrojados inseriram crônicas de autores que despontavam, como Rubem Braga, Paulo Mendes Campos, Fernando Sabino, Ledo Ivo, Clarice Lispector, entre outros, nos anos 1960 (cf. COUTINHO, 1967).

Rádio, cinema e televisão educativos foram explorados decisivamente até os anos 1980, em geral por ações centralizadoras, com

17- Principalmente a partir da Portaria 1045/1951 (programas mínimos para o ensino secundário).

18- A seção "Ensino" foi consultada em edições do Correio da Manhã publicadas na década de 1950.

19- Ano da primeira edição da obra História do Brasil: curso superior, escrita pelo autor. 
ápice durante a ditadura militar. Apesar de inspirarem projetos sociais abrangentes entre os anos 1950 e 1960, e também auxiliarem a conformar o que viria a ser a educação a distância no país, seguem com inserção limitada no terreno da educação formal, por meio de canais de circulação localizada, como TV Escola e TV Futura, ou de projetos como o atual Telecurso (ZANCHETTA, 2015). Desde o início da ditadura militar, jornais e revistas escolares se transformaram em estratégias ainda mais pulverizadas.

\section{Décadas de 1970 a 2000}

A disposição da lei 5.692/71, de levar para a escola conteúdos próximos do cotidiano, e a modernização do parque gráfico do país, graças à subvenção governamental ${ }^{20}$, favoreceriam mudanças. 0 Parecer 853/71 e a Resolução 8/71 deram forma a um programa de ensino cujas características para as séries finais do primeiro grau estavam no estímulo ao uso de diferentes linguagens na escola, incluindo os textos midiáticos (BRASIL, 1971). Nos LD voltados para o primeiro grau, ainda predominavam os textos literários, agora representados por pequenos contos, crônicas, fábulas e excertos de aventura, e com presença frequente de autores contemporâneos. Houve inserção discreta de quadrinhos, tiras, anúncios publicitários, fotojornalismo e canções da MPB contemporânea. Embora raros, encontravam-se trechos de entrevistas com personalidades, artigos e pequenas reportagens, provenientes, em geral, de revistas, cujo tempo de exposição mais longo exigia assuntos neutros ou de fôlego, como feitos tecnológicos ou problemas urbanos ${ }^{21}$. Os textos noticiosos apareciam fragmentados, com pouca ligação com as publicações de origem.

Para a abordagem de características de composição textual, investigavam-se questões formais. Era possível encontrar ferramentas de análise ainda hoje raras nos LD, como o estudo

20- Com recursos dos chamados acordos MEC/USAID, o regime militar passou a comprar, coeditar e editar LD voltados, sobretudo, aos estudantes mais pobres.

21- Graças ao tempo maior de exposição, as reportagens acabavam testadas pelo público e pela censura, antes de adaptadas para os manuais. de planos cinematográficos (cf. CASTELLO, $\mathrm{s} / \mathrm{d}$ ), mas os textos midiáticos eram seguidos de rudimentos de técnica. A técnica jornalística, por vezes tratada como "ridícula" (cf. OLIVEIRA et al., 1977, p. 15), apresentava, por outro lado, esquematismo que servia para evidenciar a possibilidade de alunos iniciantes construírem e compreenderem textos longos a partir de regras simples. A produção de textos noticiosos, falados ou escritos, solicitada pelos LD, dava sequência à proposta dos jornais escolares. 0 princípio de se levar para a escola programas educativos também continuou com o uso da televisão e do vídeo (com maior vigor nos anos 1980), com a reprodução de programas selecionados, em geral documentários e adaptações de obras literárias, dado o caráter duvidoso do conjunto da programação:

Não há quem não conheça a nossa televisão. Acusam-na de deseducadora da juventude, de disseminar no mundo uma onda de violência. Alguns chamam-na até de antítese da comunicação. E com certas razões. [...] Raríssimos são os programas aproveitáveis. Salvam-se alguns documentários, alguns telejornais, uns poucos filmes instrutivos... No mais, nossa televisão é um desfilar de novelas do mais baixo nível (com raríssimas exceções), onde avulta a violência, o ódio, a inveja, a intriga... (MACED0, 1975, p. 32).

A diversidade e o experimentalismo encontrados nos LD para o primeiro grau ocorreram em escala modesta nos manuais para o segundo grau. A busca por textos cotidianos atrelava-se a um caminho que, de acordo com o Parecer 853/71, ia do "concreto ao abstrato". À medida que avançava a escolaridade, textos mais simples e objetivos eram substituídos por textos literários. Num estágio intermediário, apareciam canções da MPB e poemas. 0 ensino de segundo grau continuou centrado na historiografia literária. Havia certo traço profissionalizante, com questões ligadas ao presente imediato, mas tal roupagem incluía autores literários contemporâneos, principalmente por 
meio da crônica, além de ofícios, cartas comerciais, requerimentos e telegramas, e outros textos utilitários antes encontrados em obras voltadas ao ensino comercial e industrial, que agora dividiam espaço marginal com frações de reportagens. A informação não verbal continuou limitada a imagens dos autores literários e a ilustrações isoladas. Na coleção para o ensino de segundo grau mais prestigiada do período (MARTOS, 1983), não constavam textos midiáticos. Na coleção mais solicitada para o primeiro grau (CEGALLA, s/d), publicada desde os anos 1970, os textos midiáticos eram ocasionais ${ }^{22}$.

Ao menos dois fatores contribuíram para o aumento do volume de textos midiáticos nos LD dos anos 1990. Aumentou o prestígio social desses textos, principalmente a partir dos 1980, com o processo de massificação da televisão e da imprensa escrita. Pesquisadores como Marcuschi (1998) e Perini $(1991,1995)$ estavam entre os otimistas com a proposta de se tomar o registro de imprensa como referência de linguagem padrão para a escola. Adotou-se ainda a noção de gênero textual como unidade de análise linguística, permitindo a valorização dos elementos estruturais e também dos fatores dialógicos dos textos e, com isso, obrigando à observação do contexto em que circulavam (BRASIL, 1997). Propostas curriculares estaduais, como a de São Paulo (1998) (estado com maior público consumidor de LD), incluíram textos jornalísticos e suas funções sociais para estudo nas últimas séries do $\mathrm{EF}$, provocando o rápido aumento do número de textos noticiosos no LD (ressalte-se ainda que as principais editoras estavam sediadas em São Paulo).

A objetividade, o vínculo direto com cotidiano e a possibilidade de participação política poderiam facilitar aos textos midiáticos tratamento apurado. Ao incorporar funções de formação para cidadania, dispostas nos Parâmetros Curriculares Nacionais (BRASIL, 1998), a escola encontrou no trabalho com meios e textos midiáticos uma espécie de "ponte para a realidade”. Mas o crescente prestígio e o espaço

22- De acordo com lista de obras mais escolhidas pelos professores publicada na revista Leia Livros, em março de 1986 (n. 41). maior não se traduziram em melhor condição de uso daqueles textos, mesmo com a seleção dos LD sendo feita, desde aquele momento, não mais pelos professores, mas por especialistas acadêmicos. No EF, persistiram as adaptações, apagando-se boa parte dos dispositivos propostos para a leitura, como autoria, títulos, subtítulos, ilustrações e mesmo trechos consideráveis de textos de imprensa (ZANCHETTA, 2004). Tiras e textos publicitários, em muito maior número que os noticiosos, substituíram a literatura e, mais tarde, frases soltas foram empregadas para ensino gramatical. Nos manuais para o EM, a presença dos textos midiáticos aumentou, mas com os mesmos problemas encontrados nos manuais do EF.

\section{Tempos contemporâneos}

A noção de gênero está assentada nas diretrizes recentes, mas a abordagem da mídia continuou limitada. Com presença constante nos livros para o EF e para o EM, tiras, textos publicitários e cartuns assumiram múltiplas funções, servindo para o ensino de noções gramaticais, exercícios de leitura, crítica, entretenimento e para conferir dinamismo ao projeto gráfico. A informação sobre a estrutura do texto de imprensa deixou de lado os equívocos e as simplificações excessivas. Mas esses textos, em boa parte, servem como depósito de conteúdos e pretexto para atividades, seguindo desvinculados do cenário midiático de onde se originam. Se antes ombreavam com ofícios, cartas e requerimentos, eles disputam agora espaço com regras para a produção de debates, mesas-redondas, entrevistas, relatos pessoais e e-mails.

Essa visão ensimesmada e ainda voltada para a reprodução, pelo estudante, das regras mínimas de produção e uso dos textos, também está relacionada à vertente instrumental do construtivismo. Em sua primeira versão, o referencial adotado para o Exame Nacional do Ensino Médio (Enem) ${ }^{23}$ preconizava competências voltadas à norma culta da língua portuguesa (BRASIL, 2000). Mas os códigos midiáticos não

23- Por conta do espaço limitado, observamos apenas as diretrizes para o EM. 
se restringem à linguagem verbal e, na maioria dos MC, a norma culta é apenas referência. É crescente a fusão de suportes e gêneros, possibilitada pelos avanços tecnológicos ${ }^{24}$. Traços sensoriais e afetivos também escapam à avaliação proposta naquelas diretrizes. A componente sensorial é explorada de forma intensa e deixa de se ligar apenas ao formato físico, para tornarse instrumento que interfere na significação dos suportes e das mensagens. 0 traço afetivo, por sua vez, busca garantir a atenção do leitor.

$\mathrm{Na}$ versão das diretrizes para o EM lançada no início da década de 2000 (BRASIL, 2000), sobre a competência relacionada à solução de problemas, está implícita a observação de certo quantum de conhecimento acerca de cenários, códigos e processos mais ou menos estáveis, desenvolvidos em currículos pré-concebidos, materializados em dado momento ${ }^{25}$, com elementos acima de diferenças culturais, enquanto os estudos sobre mídia tendem ao esquematismo se desprovidos do contexto e da ideologia ${ }^{26}$. É possível observar um roteiro concreto de conteúdos da química à literatura, mas não em termos de conteúdos midiáticos. A análise do perfil ideológico de suportes e de textos mostra-se instável diante dos assuntos vistos sob a proposta construtivista, que aborda a ruptura (ou a percepção do novo) a partir de um ângulo que diminui o papel do conflito (MIRANDA, 1995).

Versão recente das diretrizes para o EM (BRASIL, 2009) abarca a noção de gênero (competência de área 7) e também sugere explicitamente a abordagem de diferentes tecnologias da comunicação e da informação, caracterizadas por sistemas simbólicos não restritos aos textos verbais (competências de área 1 e 6). A competência de área 9 é taxativa

24- A reportagem, por exemplo, compõe-se de texto central, de cunho narrativo/descritivo/analítico, fotografias legendadas, infografia e textos menores, com remissões a textos virtuais. Esse conjunto expande as possibilidades sentido do texto principal e está organizado em projeto gráfico provocador e capaz de interagir com outros conteúdos.

25- Por quadros de conhecimentos, tomam-se, por exemplo, noções como as relacionadas a cadeias alimentares, à economia de um município, estado ou país, ao contexto em que se inscreve uma obra literária (autor, contexto de produção, gênero e filiação estética).

26- 0 conflito entre a concepção universalista e a proposta contextualizada de currículo está bem representado na Revista Educação \& Sociedade, n. 73, dez. 2000. quanto à necessidade de se compreender o universo midiático (entre outros) e suas relações com a experiência de vida das pessoas. No entanto, os avanços práticos são lentos, como se percebe na descrição das habilidades mais requintadas esperadas de alunos da $3^{\text {a }}$ série do EM, em relação a textos midiáticos, na rede estadual paulista, cujo referencial está afınado com as orientações federais:

- [os alunos] estabelecem relações de causa/consequência entre informações pressupostas em notícia;

- organizam em uma dada sequência proposições desenvolvidas pelo autor em artigo de divulgação;

- inferem a tese defendida, em artigo de opinião, com base na análise da argumentação construída pelo autor (SEE) SP, 2009, p. 90).

A análise esperada sugere inferências internas ou ligações de sentido estabelecidas a partir de informações encontradas na superfície e nos limites de um só texto. Ficam de fora aspectos como origem, condições de produção, contexto e condições de circulação, intertexto, previsão de interlocução, entre outros fatores.

A entrada da mídia no LD ainda ocorre de maneira a servir ao currículo regular. Tomemos como exemplo a coleção Português: Linguagens (PL) (CEREJA; MAGALHÃES, 2012, 2013), a mais representativa dos dias de hoje: 1) em 2014, foi a coleção com maior aceitação entre escolas e professores no país, no EF e no $\mathrm{EM}^{27}$ (foi também protagonista em versões anteriores dos programas governamentais); 2) a coleção acompanhou todo o percurso das avaliações do PNLD e PNLEM, refletindo, em boa medida, a evolução da própria crítica acadêmica aos

27- Sobre as últimas séries do EF, os números de distribuição da coleção PL eram cerca de 50\% maiores do que os da segunda coleção mais procurada. (cf. <file:///C:/Users/user/Downloads/colecoes\%20mais\%20 distribuidas\%20pnld\%202014\%20(2).pdf>. Acesso em: 02 set. 2014). A opção pela coleção PL mostrou-se ainda mais pronunciada no EM (cf. $<$ file:///C:/Users/user/Downloads/colecoes\%20mais\%20distribuidas\%20 pnld\%202014\%20(2).pdf>. Acesso em: 02 set. 2014). 
livros didáticos ${ }^{28}$; 3) é uma das únicas coleções

28- A coleção para o EM teve a primeira edição em 1990. A coleção para o EF foi lançada em 1998. a atender desde o EF até o EM. Eis o elenco de gêneros presentes na coleção PL:

Quadro 1 - Gêneros textuais presentes na coleção Português: Linguagens ${ }^{29}$

\begin{tabular}{|c|c|c|c|c|c|c|c|}
\hline & $5^{a}$ & $6^{a}$ & $7^{a}$ & $8^{a}$ & $1^{0}$ & $2^{\circ}$ & $3^{\circ}$ \\
\hline Textos instrucionais* & 4 & 4 & 4 & 4 & 10 & 14 & 6 \\
\hline Verbetes* & 22 & 15 & 8 & 8 & 45 & 26 & 48 \\
\hline Sugestões de leitura* & 15 & 16 & 10 & 11 & 32 & 54 & 67 \\
\hline Fotografias & 34 & 43 & 52 & 57 & 88 & 67 & 7 \\
\hline Artes (pinturas, esculturas etc.) & 10 & 11 & 5 & 13 & 68 & 80 & 71 \\
\hline Ilustrações diversas & 123 & 100 & 97 & 86 & 104 & 59 & 71 \\
\hline Tiras & 53 & 47 & 32 & 35 & 34 & 45 & 21 \\
\hline Propagandas & 15 & 15 & 29 & 28 & 22 & 27 & 28 \\
\hline Cenas artísticas & 13 & 21 & 10 & 16 & 20 & 33 & 17 \\
\hline Fotos de autores & 6 & 3 & 2 & 3 & 11 & 23 & 24 \\
\hline Capas (discos, CDs, livros etc.) & 13 & 19 & 7 & 7 & 29 & 21 & 38 \\
\hline Cartuns & 15 & 6 & 11 & 7 & 4 & 4 & 5 \\
\hline Charges & - & - & - & - & 1 & 1 & - \\
\hline Caricaturas (de escritores) & 1 & 2 & - & 2 & - & 4 & 20 \\
\hline $\mathrm{HQ}$ & 4 & 1 & - & - & - & - & - \\
\hline Infografia & 1 & - & 6 & 6 & 8 & 4 & 4 \\
\hline Poesia & 21 & 50 & 25 & 31 & 113 & 50 & 105 \\
\hline Verbetes (por terceiros) & 30 & 15 & 10 & 6 & 56 & 37 & 37 \\
\hline Romance & 3 & 11 & 1 & 3 & 8 & 10 & 19 \\
\hline Conto & 3 & 2 & 1 & 11 & 1 & 9 & 1 \\
\hline Crônica & 3 & 1 & 16 & 7 & 8 & 6 & 4 \\
\hline Artigo e variações & 2 & 1 & 6 & 12 & 13 & 9 & 28 \\
\hline Nota/notícia & 4 & 6 & 6 & 6 & 13 & 12 & - \\
\hline Fábula & 5 & 3 & - & 1 & 1 & 1 & 1 \\
\hline Reportagem & 1 & 2 & 7 & 8 & 3 & 3 & - \\
\hline Canção & - & - & 3 & 2 & 1 & 1 & 1 \\
\hline Anedota/adivinha & 16 & 5 & 13 & 8 & - & - & - \\
\hline Entrevista/depoimento & 1 & 5 & 2 & - & - & 1 & 2 \\
\hline Divulgação científica & - & - & 2 & 1 & 6 & 2 & 1 \\
\hline Carta & 1 & - & 8 & - & 1 & - & 9 \\
\hline
\end{tabular}

Fonte: elaborado pelo autor.

29- A coleção conta ainda com os seguintes textos: comentário (6 inserções), teatro (6), resenha (5), outros textos (6), diário (5), cordel (4), receitas (4), sermão (3), cartaz (3), lei (3), e-mail (3), debate (2), sinopse (1), manifesto (1), bilhete (1), convite (1), relato pessoal (1), epístola (1) e resumo (1). 
Essa configuração não espelha o conjunto da produção didática atual, mas a onipresença da coleção PL deixa entrever aspectos da cultura escolar, principalmente se se leva em conta o fato de se tratar de obra que vem sendo ajustada há cerca de duas décadas. 0 quadro revela um traço determinante: a opção por textos não verbais, que aparecem em maior número e em diversos gêneros. Entre os textos midiáticos, prevalecem tiras e propagandas. Os artigos estão em evidência, muito em razão das exigências de avalições externas. Nas demais coleções, os textos midiáticos, inclusive tiras e propagandas, aparecem com volume mais discreto (mantendose a prioridade aos textos literários).

0 tratamento da mídia continua hesitante não apenas pelo modo como os LD lançam mão de seus textos, mas pelas omissões. Os avanços tecnológicos e de impressão têm sido utilizados para, além de ilustrar de maneira pronunciada expedientes literários e gramaticais, dinamizar gêneros vazios por si mesmos, como seminários e mesas-redondas, muitas vezes nivelados por igual com textos jornalísticos. Os mesmos avanços não facilitaram a entrada de outros gêneros: novelas, telejornais, séries de ficção, cinema (exceto a partir de resenhas e menção a filmes), documentários, programas de auditório, suportes baseados na internet, entre outros, continuam tacitamente ignorados.

\section{Considerações finais}

Para uma escola ainda não acostumada a conviver com os suportes originais dos textos midiáticos, analisar contextos ampliados é desafıo distante. Para a compreensão de texto publicado num sítio de notícias, o contexto pode ser mais determinante do que as relações internas de sentido. A notícia curta e pouco analítica, títulos contundentes, imagens, gráfıcos, links diversos, associação com outros temas, o ranqueamento das notícias mais lidas: tais dispositivos de leitura, mesmo situados numa só tela, remetem o leitor para as bordas, favorecendo a observação topológica e intertextual. 0 texto e seus dispositivos tornam-se pontos de passagem. 0 cenário de informação telegráfica, com predomínio de notas jornalísticas e mensagens curtas em redes sociais, também dificulta o enfrentamento didático desse universo.

A opção por veículos e estratégias governamentais próprias minimizou-se a partir dos anos 1980. 0 incentivo à produção de jornais e revistas escolares persiste em atividades fluidas de produção de textos sugeridas pelos LD. Do escolanovismo ao construtivismo, a estratégia de tomar o texto midiático como pretexto para a produção textual ainda é destacada. A popularização e o prestígio dos gêneros comuns na mídia não foram suficientes para garantir a eles tratamento programático. A funcionalização dos textos midiáticos no cotidiano das salas de aula tende a mantê-los distantes dos contextos originais, comprometendo a visão histórica. Citem-se mesmo os numerosos anúncios e tiras, sobre os quais há pouca referência quanto ao contexto de produção, às questões técnicas empregadas para a codificação (como traço, enquadramento, cor, luz), à utilização de repertório cultural (afinado com o público a que se destinam), entre outros expedientes. Notese ainda que entre os únicos temas recorrentes nas notícias reproduzidas pelos LD nos últimos cinquenta anos estão curiosidades de ordem diversa e novidades tecnológicas - assuntos que se ligam mais à ideia de entretenimento do que ao processo de produção do jornalismo.

Avanços tecnológicos ampliam as possibilidades, mas as limitações normativas perpetuam as dificuldades. Nos moldes do Enem, por exemplo, é impensável sugerir ao estudante a análise de notícia ou reportagem publicada por um telejornal, por um sítio da internet ou por um jornal impresso, exceto de forma simplificada. Em parte por isso, a tendência mais prestigiada na pesquisa brasileira sobre comunicação e educação, a chamada educomunicação, para enfrentar os desafios da informação nos dias de hoje sugere mudanças radicais no desenho da escola (cf. SOARES, 2011), mas, de algum modo, recupera algo já testado na história da escola: 
fazer com que os estudantes reflitam sobre a comunicação midiática a partir da produção escolar de suportes e textos dessa área.

Embora não tenha sido a única, historicamente, a disciplina de português concentrou o maior volume de trabalho pedagógico com suportes e textos midiáticos, e sempre os subordinou às noções do currículo regular. A criação de uma disciplina específica para se tratar a mídia poderia significar um salto maior. Young (2011) compara o aprendizado de uma disciplina ao aprendizado de violino: quando o aluno consegue tocar, tem acesso a um universo musical bem maior do que aquele propiciado pela destreza no uso do instrumento. 0 ensino relacionado à mídia, disposto em disciplina específica, poderia levar o estudante ao domínio de recursos de produção e também o inserir no debate sobre as coisas públicas, facilitando a análise de contexto mais abrangente. Desde 2010, tramita no Congresso Nacional projeto de lei (PL-7450/10), que propõe a inclusão da disciplina Leitura e Educação para as Mídias no currículo da escola básica, mas essa ideia está longe de proporcionar debate promissor, dada a justificativa rasa da proposta e o histórico do proponente: Eduardo Cunha. Além disso, até o início de 2014, aquele projeto disputava atenção com outras 34 propostas de disciplinas, projetos ou temáticas para o currículo, como Educação para o Pensar e Ensino de Esperanto.

Outra sugestão diz respeito à criação de espaços de produção on-line de material didático específico, utilizando-se estruturas já disponíveis no âmbito de governos e de universidades, e a experiência acumulada por estudiosos há décadas no Brasil ${ }^{30}$. Tome-se, nessa linha, o exemplo do Centre de Liaison de l'Enseignement et des Médias d'Information (Clemi), ligado ao governo francês, com o desenvolvimento de conteúdos atentos à agenda midiática e à interlocução com professores, alunos e currículo regular.

Num país em que os vestibulares e o Enem lançam mão de textos com até trinta linhas (contra textos de cem linhas cobrados no Pisa) e em que apenas um quarto da população é capaz de ler textos longos, relacionar suas partes, comparar e interpretar informações, distinguir fato de opinião e realizar inferências e síntese (INSTITUTO..., 2009), o domínio sobre a reportagem poderia ser tomado como objetivo de fundo para a disciplina de português. 0 projeto gráfico mais complexo desse gênero dificulta a fragmentação e pode incentivar a preservação das condições originais dos suportes e dos textos.

Nos dias de hoje, em que os conteúdos do LD migram para o ambiente digital, é possível pensar que haverá mais espaço e recursos para o tratamento dos textos midiáticos, incluindo os mais complexos, como aqueles comuns ao jornalismo. A história da escola, entretanto, caminha com passos mais lentos e ainda em outra direção.

30- São exemplos o GT Educação e Comunicação, ligado à ANPEd; a Sociedade Brasileira de Estudos Interdisciplinares da Comunicação (Intercom); o Seminário Nacional o Professor e a Leitura do Jornal (Unicamp e ALB); a licenciatura em educomunicação promovida pela ECA/USP. 


\section{Referências}

ALMEIDA, Napoleão Mendes de. Antologia remissiva: excertos de escritores de língua portuguesa para a $3^{\mathrm{a}}$ e para a $4^{\mathrm{a}}$ série ginasial. São Paulo: Saraiva, 1946.

ANTONACCI, Maria Antonieta (Coord.) Trabalho, cultura, educação: Escola Nova e Cinema Educativo nos anos 1920/1930. 1993. Disponivel em: <http://revistas.pucsp.br/index.php/revph/article/viewFile/12111/8773>. Acesso em: 1 fev. 2015.

BAHIA, Juarez. Jornal, história e técnica. v. 1. São Paulo: Ática, 1990.

BEKER, Gretchen. TV Educativa: balanço das realizações e perspectivas. Revista Brasileira de Estudos Pedagógicos, Brasília, DF. n. 108, p. 280-295, out./dez. 1967.

BRASIL. Decreto-lei n. 1.006, de 30 de dezembro de 1938. Coleção de Leis do Brasil, Brasília, DF, v. 4, p. 350, 1938. Disponível em: <http://www2.camara.leg.br/legin/fed/declei/1930-1939/decreto-lei-1006-30-dezembro-1938-350741-norma-pe.html>. Acesso em: 15 fev. 2015.

BRASIL. Instituto Nacional de Estudos Pedagógicos. Conferências internacionais de instrução pública. Brasília, DF: Ministério da Educação e Cultura: INEP, 1965. Disponível em: <http://www.dominiopublico.gov.br/download/texto/me002529.pdf>. Acesso em: 31 jan. 2015.

BRASIL. Ministério da Educação. Parâmetros curriculares nacionais: ensino médio. Brasília, DF: MEC, 2000. Disponível em: <http://portal.mec.gov.br/seb/arquivos/pdf/14_24.pdf>. Acesso em: 19 mar. 2015.

BRASIL. Ministério da Educação. PCN+ ensino médio: orientações educacionais complementares aos parâmetros curriculares nacionais. Brasília, DF: MEC, 2009. Disponivel em: <http://portal.mec.gov.br/seb/arquivos/pdf/linguagens02.pdf>. Acesso em: 19 mar. 2015.

BRASIL. Parecer 853/71, de 12 de novembro de 1971, do CFE. Núcleo Comum para os Ensinos de $1^{\circ}$ e $2^{\circ}$ graus. A doutrina do currículo na lei 5.692. Documenta, Rio de Janeiro, n. 132, nov. 1971. Disponível em: <http://www.histedbr.fae.unicamp. br/navegando/fontes_escritas/7_Gov_Militar/parecer\%20n.\%20853-1971\%20n\%FAcleo\%20comum\%20para\%20os\%20 curr\%EDculos....pdf>. Acesso em: 23 abr. 2014.

BRASIL. Secretaria de Educação Fundamental. Parâmetros curriculares nacionais: introdução: $5^{\mathrm{a}}$ a $8^{\mathrm{a}}$ séries. Brasilia, DF: MEC/ SEF, 1998.

BRASIL. Secretaria de Educação Fundamental. Parâmetros curriculares nacionais: língua portuguesa. Brasilia: MEC/SEC, 1997.

BRASIL. Secretaria de Educação Fundamental. Parâmetros curriculares nacionais: terceiro e quarto ciclos do ensino fundamental: língua portuguesa. Brasília, DF: MEC/SEF, 1998.

CALABRE, Lia. Políticas públicas culturais de 1924 a 1945: o rádio em destaque. Revista Estudos Históricos, São Paulo, 2003.

CÂMARA JR., Joquim Mattoso. Manual de expressão oral e escrita. Rio de Janeiro: J. Ozon, 1961.

CANDIDO, Antonio. Literatura e sociedade. São Paulo: Nacional, 1985.

CASTELLO, Alexandre et al. Isto é comunicação. São Paulo: IBEP, [s. d.].

CEGALLA, Domingos Paschoal. Português fundamental. São Paulo: Nacional, [s. d.]. 
CEREJA, William Roberto; MAGALHÃES, Thereza Cochar. Português: Linguagens. São Paulo: Saraiva, 2012. 4 v.

CEREJA, William Roberto; MAGALHÃES, Thereza Cochar. Português: linguagens. São Paulo: Saraiva, 2013. 3 v.

CHAVES, Miriam Waidenfeld. 0 papel da igreja na educação escolar masculina na década de 1950. Cadernos de Pesquisa, São Paulo, v. 42, n. 146, p. 518-537, maio/ago. 2012.

COUTINHO, Afrânio. Antologia brasileira de literatura. Rio de Janeiro: Livros Escolares, 1967.

COUTINHO, Afrânio. 0 ensino de literatura no curso secundário. Revista Brasileira de Estudos Pedagógicos, Brasília, DF, v. 21, n. 54, p. 03-15, abr./jun. 1954.

CURY, Carlos Roberto Jamil. Alguns apontamentos em torno da expansão e da qualidade do ensino médio no Brasil. Cadernos Cedes, São Paulo, n. 25, p. 45-62, 1991.

FERREIRA, Rita de Cássia Cunha. A Comissão Nacional do Livro Didático durante o Estado Novo (1937-1945), 2007. Dissertação (Mestrado em História) - Faculdade de Ciências e Letras da Universidade Estadual Paulista "Júlio de Mesquita Filho" (Unesp), Assis 2007.

FREITAG, Bárbara; MOTTA, Valéria Rodrigues; COSTA, Wanderley Ferreira da. 0 livro didático em questão. São Paulo: Ática, 1989.

FULCHIGNONI, Enrico. A ajuda dos elementos audio-visuais na educação na América. Revista Brasileira de Estudos Pedagógicos, Brasilia, DF, v. 19, n. 49, p. 13-27, jan./mar. 1953.

GOMES, Antônio Osmar. Através de revistas e jornais. Revista Brasileira de Estudos Pedagógicos, Brasília, DF, n. 31, p. 555556, nov./dez. 1947.

INSTITUTO PAULO MONTENEGRO. Indicador de Alfabetismo Funcional - INAF. São Paulo: Ação Educativa. 2009. Disponível em: <http://www.ipm.org.br/download/inaf_brasil2009_relatorio_divulgacao_final.pdf>. Acesso em: 07 dez. 2009.

LEAL, Antonio de Souza. Grafemos... São Paulo: José do Couto, 1955.

LEITE, Marcelo. Maturidade. Folha de S. Paulo, 19 mar. 1995. Disponível em: <http://www1.folha.uol.com.br/folha/ombudsman/ omb_19950319_1.htm>. Acesso em: 5 jun. 2014.

LOURENÇO FILHO, Manoel Bergstron. Variações sobre um velho tema. Revista Brasileira de Estudos Pedagógicos, Brasília, DF, v. 30, n. 71, p. 30-45, jul./set. 1958.

MACEDO, José Armando. A redação do vestibular. São Paulo: Moderna, 1975.

MARCUSCHI, Luiz Antônio. Compreensão textual como trabalho criativo. In: UNESP. Universidade Estadual Paulista "Júlio de Mesquita Filho". Caderno de formação: conteúdos e didática de língua portuguesa e literatura. São Paulo: Cultura Acadêmica, 2011. p. 89-116.

MARCUSCHI, Luiz Antônio. Nove teses para uma reflexão sobre a valorização da fala no ensino de língua. Revista da ANPOLL, Florianópolis, n. 4, p. 137-156, jan./jun. 1998.

MARTOS, Cloder Rivas. PAl - Processo Auto-Instrutivo: língua e literatura: 2º grau. São Paulo: Saraiva, 1983.

MELO, Orlando Ferreira de. Comentários sobre a monografia 'A educação em Santa Catarina'. Revista Brasileira de Estudos 
Pedagógicos, Brasília, DF, n. 61, p. 91-112, jan./mar. 1956.

MICELI, Sergio. Entre o palco e a televisão. In: IBGE. Instituto Brasileiro de Geografia e Estatística. Estatísticas do século XX. Rio de Janeiro: IBGE, 2003. p. 275-300.

MIRANDA, Marília Gouveia. Trabalho, educação e construtivismo: a redefinição da inteligência em tempos de mudanças tecnológicas. Educação \& Sociedade, Campinas, v. 51, p. 275-330, 1995.

OLIVEIRA, Elisabeth Brait Rodrigues de; NEGRINI, José Luiz da Costa Aguiar; LOURENÇO, Nina Rosa da Penha. Encontro com a linguagem: $2^{\circ}$ grau. São Paulo: Atual, 1977.

PERINI, Mario Alberto. Gramática descritiva do português. São Paulo: Ática, 1995.

PERINI, Mario Alberto. Para uma nova gramática do português. São Paulo: Ática, 1991.

PIETRI, Émerson de. Sobre a constituição da disciplina curricular de língua portuguesa. Revista Brasileira de Educação, São Paulo, v. 15, p. 70-83, jan./abril, 2010.

RAZZINI, Marcia de Paula Gregorio. 0 espelho da nação: a Antologia Nacional e 0 ensino de português e de literatura (18381971). Tese (Doutorado em Letras) - Instituto de Estudos da Linguagem da Universidade Estadual de Campinas (Unicamp), Campinas, 2000.

RBEP. Revista Brasileira de Estudos Pedagógicos. I Congresso Estadual de Educação (Estado de São Paulo). Revista Brasileira de Estudos Pedagógicos, Brasília, DF, v. 27, n. 65, p. 101-114, 1957.

RBEP. Revista Brasileira de Estudos Pedagógicos. Uma investigação sobre jornais e revistas infantis. Revista Brasileira de Estudos Pedagógicos, Brasília, DF, n. 5, p. 255-275, nov. 1944.

RBEP. Revista Brasileira de Estudos Pedagógicos. Uma investigação sobre jornais e revistas infantis (IV). Revista Brasileira de Estudos Pedagógicos, Brasília, DF, v. 3, n. 8, p. 223-240, fev. 1945.

ROJO, Roxane. Gêneros de discurso/texto como objeto de ensino de línguas: um retorno ao trivium? In: SIGNORINI, Inês (Org.) [Re] discutir texto, gênero e discurso. São Paulo: Parábola, 2008. p. 73-108.

ROMANELLI, Otaíza de Oliveira. História da educação no Brasil (1930/1973). Petrópolis: Vozes, 1986.

RSR. Regulamento dos Serviços de Radiodifusão. Decreto n. 52.795, de 31 de outubro de 1963. Disponível em: <http://www. mc.gov.br/legislacao/por-ano/anos-anteriores/decreto-n-52-795-de-31-de-outubro-de-1963>. Acesso em: 15 dez. 2013.

SÃO PAULO. Secretaria de Estado da Educação. Proposta curricular para o ensino de língua portuguesa: ensino fundamental. São Paulo: SEE, 1998.

SECOM. Secretaria de Comunicação Social. Pesquisa brasileira de mídia 2014: hábitos de consumo de mídia pela população brasileira. Brasilia, DF: Secom, 2014. Disponível em: <http://observatoriodaimprensa.com.br/download/ PesquisaBrasileiradeMidia2014.pdf>. Acesso em: 15 mar. 2014.

SEE-SP. Secretaria de Estado da Educação de São Paulo. Saresp 2009: sumário executivo. São Paulo: SEE/FNDE, 2009.

SOARES, Magda. A escolarização da literatura infantil e juvenil. In: MARTINS, Aracy Alves; BRANDÃO, Heliana Maria Brina; MACHADO, Maria Zélia Versiani (Org.). Escolarização da leitura literária. Belo Horizonte: Autêntica, 2001. p. 17-48. 
SOARES, Ismar de Oliveira. Educomunicação: 0 conceito, o profissional, a aplicação - contribuições para a reforma do Ensino Médio. São Paulo: Paulinas, 2011.

SODRÉ, Nelson Werneck. Historia da imprensa no Brasil. Rio de Janeiro: Civilização Brasileira, 1966.

SOUZA, Roberto Acízelo. 0 império da eloquência. Rio de Janeiro: EdUERJ: EdUFF, 1999.

XAVIER, Libânea. Educação e imprensa carioca na década de 1950. In: SIMPÓSIO NACIONAL DE HISTÓRIA - ANPUH, 23., 2005, Londrina. Anais... Londrina: Anpuh, 2005. Disponível em: <http://anpuh.org/anais/wp-content/uploads/mp/pdf/ANPUH.S23.0580. pdf>. Acesso em: 2 abr. 2015.

YOUNG, Michael F. D. 0 futuro da educação em uma sociedade o conhecimento. Revista Brasileira de Educação, Rio de Janeiro, v. 16, n. 48, p. 609-623, set./dez. 2011

ZANCHETTA JR., Juvenal. Os temas educação, escola e conhecimento nas leis e nas práticas midiáticas brasileiras. Educação \& Sociedade, Campinas, v. 36, n. 133, p. 1119-1136, dez. 2015.

ZANCHETTA JR. Juvenal. Gêneros textuais de imprensa no livro didático. Revista Leitura, Campinas, v. 43, p. 13-19, 2004.

Recebido em: 07.05.2015

Aprovado em: 16.09.2015

Juvenal Zanchetta Junior é professor do Departamento de Educação da Universidade Estadual Paulista "Júlio de Mesquita Filho" (Unesp) Assis, ligado ao Programa de Pós-Graduação em Educação da Unesp de Marília. 